\title{
Russell-Names: An Introduction to Millian Descriptivism
}

\author{
Stefano Predelli ${ }^{1}$
}

Received: 13 August 2015 / Accepted: 29 November 2015 / Published online: 21 December 2015 (C) The Author(s) 2015. This article is published with open access at Springerlink.com

\begin{abstract}
This essay studies the semantic properties of what I call Russell-names. Russell-names bear intimate semantic relations with descriptive conditions, in consonance with the main tenets of descriptivism. Yet, they are endowed with the semantic properties attributed to ordinary proper names by Millianism: they are rigid and non-indexical devices of direct reference. This is not an essay in natural language semantics, and remains deliberately neutral with respect to the question whether any among the expressions we ordinarily classify as proper names behave as Russellnames. Its aim is rather that of casting a new light on the traditional debate about descriptivism on the one hand, and, on the other, what is commonly understood as a radically anti-descriptivist approach. From the viewpoint of descriptivism, the conceivability of Russell-names provides welcome relief from the pressure exerted by considerations at odds with a flaccid and/or indexical treatment of proper names. Conversely, from a Millian standpoint, the conceivability of Russell-names indicates that the Millian stance, far from providing a meagre picture of names as 'mere tags', is at least in principle consistent with the recognition of their semantic bonds with richer descriptive material. The Appendix provides a formal treatment of Russellnames within a model theoretic semantics for indexical intensional languages, developed within an original 'double-context' framework.
\end{abstract}

Keywords Semantics $\cdot$ Context $\cdot$ Names

Stefano Predelli

stefano.predelli@nottingham.ac.uk

1 Department of Philosophy, University of Nottingham, Nottingham NG7 2RD, UK 
This essay is devoted to the discussion of expressions of a particular, and, as far as I can tell, not previously discussed type. I call them Russell-names.

The occurrence of 'Russell' in 'Russell-name' is an allusion to certain aspects of Bertrand Russell's theory of names, which have provided the initial inspiration for my project-first and foremost, his idea that 'ordinary proper names' are abbreviations of definite descriptions. ${ }^{1}$ Admittedly, this 'initial inspiration' yields me to conclusions that bear little resemblance with anything Russell may have wished to say about ordinary names, or for that matter about any other expression. But my aims here are neither historical nor exegetical: rather, my superficial homage to Russell serves as a reminder of the descriptivist aspects in his analysis of proper names, which, in a sense that will hopefully become clearer as I proceed, continue to reverberate in my treatment of Russell-names. ${ }^{2}$

My initial gesture towards the descriptive dimension of Russell-names is meant to provide a noteworthy contrast with the other part of the moniker I have chosen for my concoctions: Russell-names deserve the label 'names' because they are intended to conform to what I take to be the fundamental semantic properties of proper names, namely their rigidity, direct-referentiality, and non-indexicality. These are admittedly not properties that everybody happily attributes to proper names. Yet, my aim here is not that of defending my own views about names: in principle, what I propose remains consistent with the notions that none, some, or perhaps all among the expressions commonly classified as names are Russell-names. Still, my point is also not that of a mere formal exercise, with no bearing on the current debate on proper names: although, in a sense, my treatment of Russell-names follows unashamedly descriptive lines, these expressions do nevertheless conform to the semantic pattern customarily associated with traditionally rabidly anti-descriptivist approaches, first and foremost my favourite Millian treatment of names as rigid and non-indexical referential devices. ${ }^{3}$

\footnotetext{
${ }^{1}$ See for instance [40, 41] and [42].

${ }^{2}$ The form of descriptivism at issue in what follows strikes me as Russellian also because of its insistence on certain semantically relevant relationships between our respective explananda (ordinary names in Russell's case, Russell-names in mine) and descriptively well-endowed expressions - as opposed to, say, Frege-inspired descriptive senses. The apparatus I put forth in what follows may nevertheless be amenable to developments and amendments consistent with a variety of alternative versions of the descriptivist standpoint. An unrelated historical note is also appropriate at this stage: although I (loosely) follow some of Russell's insights about the relationships between names and descriptions, I take on board without further ado a relatively non-Russellian approach to the latter (see Section 2); an analysis closer to the letter of Russell's treatment of definite descriptions should nevertheless be easily derivable from what I write, with opportune modifications and adjustments.

${ }^{3}$ In the previous paragraph, I described my views on proper names as also committed to the idea that these expressions are devices of direct reference. Direct reference is a position within the framework of socalled propositional semantics, namely the notion that sentences containing occurrences of proper names express singular propositions. Since (i) the main ideas in what follows may be presented from the simpler and more familiar viewpoint of an intensional semantics for indexical languages, and (ii) these ideas may easily be rephrased in propositional terms, the notion of direct-reference remains in the background in my exposition, and is relegated to a few footnotes (see in particular footnotes 10,12, 16, and 19). For considerations on the relationships between direct reference and rigidity see $[9,21,22,27,38,43,44]$ and [28].
} 
When it comes to proper names, then, my conclusion is ecumenical. From the viewpoint of descriptivism, the conceivability of Russell-names provides welcome relief from the pressure exerted by considerations at odds with a flaccid and/or indexical treatment of proper names: even if the arguments in favour of Millianism are on the right track, so I conclude, not all versions of descriptivism should thereby be abandoned. Conversely, from a Millian standpoint, the conceivability of Russellnames indicates that the Millian stance, far from providing a meagre picture of names as 'mere tags', is at least in principle consistent with the recognition of their semantic bonds with richer descriptive material: the conclusion that certain expressions are non-indexical devices of rigid designation does not entail a picture in which their semantic properties are exhausted by their referential profile.

The first three sections of this essay are devoted to a preliminary informal introduction of the main ideas guiding my treatment of Russell-names: the notion of 'abbreviation', the sense in which Russell-names are 'associated with' definite descriptions, and the double-context framework I develop for their semantic analysis. Sections 4, 5, and 6 provide a more rigorous formal presentation of these ideas, and of their consequences for the relationships between descriptivism and Millianism. The Appendix puts forth a simple artificial language as a test study for the model-theoretic development of my double-context semantics, and as a presentation of the formal properties of the main concepts introduced throughout this essay.

\section{Preliminaries A: Abbreviations and Associations}

As far as I can tell, Russell is not particularly explicit when it comes to the relationship of abbreviation allegedly holding between ordinary proper names and definite descriptions. In my Russell-inspired account, the idea of abbreviation is glossed in terms of a certain relationship between (i) utterances of sentences involving Russellnames and (ii) certain syntactic constructs appropriate for their semantic evaluation. This section is devoted to an informal explanation of the sort of relationship I have in mind, and of the sense in which the syntactic constructs mentioned in (ii) are 'appropriate for' the semantic evaluation of utterances of Russell-names. After a few additional preliminaries in Sections 2 and 3, these ideas are studied in greater detail in Section 4, before my official treatment of Russell-names in Section 5.

Consider a community of Russell-speakers, that is, a community of users of a Russell-language involving Russell-names. The Appendix at the end of this essay presents a simple fragment as an exemplar of a Russell-language, and discusses its semantic properties from the viewpoint of the formal framework I introduce in Section 3. At this initial stage, it is however pedagogically convenient to begin with an informal sketch of a Russell-language, temporarily assumed to be indistinguishable from a simple fragment of ordinary English, with the possible exception of the occurrence of Russell-names within its lexicon. In particular, I adopt as my Russellname of choice the expression 'Bismarck' (in italics, so as to distinguish it from the ordinary proper name 'Bismarck'), and I focus on a Russell-speaker's utterance $u_{1}$ of

Bismarck was a conservative. 
This section continues with a preliminary discussion of what (1) abbreviates on the occasion of $u_{1}$, and of the sense in which the abbreviated construct provides the basis for the semantic analysis of that utterance. ${ }^{4}$

As may already be apparent from my mention of 'occasions of utterance', the choice of what is being abbreviated by (1) on the occasion of $u_{1}$ is for me a contextdependent business. In particular, I assume that an utterance $u$ by a Russell-speaker is suitably connected with an association $a$, and that the abbreviation appropriate on the occasion for $u$ depends on the properties of its connected association $a$. The details in the informal idea of a 'connection' are of no immediate relevance at this stage, and their discussion may safely be relegated to a few footnotes. ${ }^{5}$ As for the target of the connection-relation, the following informal understanding of associations suffices for the purpose of this introduction (see Section 4 for a more detailed presentation).

Informally, think of an association as an utterance of a sentence of the form: let Russell-name $r$ be associated with description $d .{ }^{6}$ In particular, taking inspiration from Russell's treatment of the ordinary proper name 'Bismarck', suppose that the aforementioned utterance $u_{1}$ is connected with the association: let the Russell-name 'Bismarck' be associated with the description 'the first Chancellor of the German Empire'. I refer to $d$, in this case 'the first Chancellor of the German Empire', as the associated description for the Russell-name $r$, here 'Bismarck', as it occurs on that occasion. $^{7}$

Let then $S_{r}$ be a sentence containing occurrences of a Russell-name $r$, and let $u_{r}$ be an utterance of $S_{r}$ with $d$ as $r$ 's associated description. I take $S_{r}$, as it occurs on that occasion, to be the abbreviation of a sentence resulting from substituting each occurrence of $r$ in $S_{r}$ with an expression 'involving' $d$, in a sense of 'involvement' more fully investigated as I proceed. So, the sentence (1), as uttered in the aforementioned circumstances for $u_{1}$, is the abbreviation of a construct of the form

(2) ... the first Chancellor of the German Empire was a conservative,

that is, it is the abbreviation of the result of substituting the occurrence of 'Bismarck' in (1) with an expression involving the description associated with that Russell-name on that occasion.

\footnotetext{
${ }^{4}$ I proceed by focusing on examples involving occurrence of one Russell-name; my comments are easily generalizable to more complex instances.

${ }^{5}$ See footnotes 7 and 24 .

${ }^{6}$ Given appropriate conditions-I leave aside the interesting but semantically tangential issues pertaining to the type of speech act at issue in the case of associations, and of the requirements for its felicitous performance.

${ }^{7}$ Taking this scenario as exemplar, the following two families of approaches to the idea of connection (possibly among others) remain compatible with the approach I pursue in this essay. (i) According to a subjectivist view, connections are affairs within the speaker's mental domain, as in a Russell-speaker's recollection, when using 'Bismarck', of her previous decision to associate any future token of that expression with 'the first Chancellor of the German Empire'. (ii) According to a deferential alternative I find more palatable, a Russell-speaker's utterance of 'Bismarck' is connected with a possibly distant event, such as someone's association of 'Bismarck' with 'the first Chancellor of the German Empire', for instance due to that utterance's position within a wider socio-linguistic network, or its occurrence within a 'chain of transmission' originating with that association. Deferentialists may do worse than studying the considerable debate on the so-called 'Causal Theory' of proper names-see among many [9, 11, 13-15, 25] and [10].
} 
Since $u_{1}$ is an utterance of a sentence containing a Russell-name, its semantic profile ought to reflect the sort of semantic properties that I have assumed to be appropriate for these expressions. In particular, $u_{1}$ ought to bear properties consistent with a rigid and non-indexical approach to 'Bismarck', in agreement with my assumption that Russell-names conform to the Millian pattern for ordinary proper names. Since I have also anticipated that the semantic properties of $u_{1}$ depend on the semantic interpretation of what is being abbreviated on that occasion, this much imposes important constraints on the completion of (2): what is desired is a sentence which, if suitably interpreted, is able to render the sort of verdicts I expect to be appropriate for $u_{1}$. Accordingly, the next two sections sketch a slightly more accurate presentation of what is being abbreviated by a Russell-speaker's utterance, and of the semantic resources needed for its interpretation.

Section 2 begins with a brief discussion of an initially promising but ultimately inadequate strategy: the idea that constructs such as (2) are to be developed by embedding the definite description, in this case the associated description for 'Bismarck', within the scope of the operator 'dthat'. Though inadequate, this dthat-gambit provides a pedagogically useful term of contrast with my own proposal, informally introduced in Section 3 and more fully investigated in the second half of this essay.

\section{Preliminaries B: Rigidity and the Dthat-Gambit}

Take then (1) again, and my incomplete presentation of what it abbreviates on the occasion of $u_{1}$ :

(1) Bismarck was a conservative.

(2) ... the first Chancellor of the German Empire was a conservative.

As mentioned above, the relation of abbreviation is of semantic relevance, in the sense that the semantic properties of an utterance are to be derived from the interpretation of what is being abbreviated on that occasion. A more detailed explanation of this idea will have to wait until Section 4, after the discussion of certain subtleties that are best left aside at this stage. Still, even now, it ought to be sufficiently clear that the ellipsis at the beginning of (2) may not be understood as a typographically idle flourish. In other words: it ought to be sufficiently clear that what is being abbreviated on the occasion for $u_{1}$ is not simply what results from substituting 'Bismarck' with its associated description, as in

(3) the first Chancellor of the German Empire was a conservative.

This is so because, at least given a standard approach to the expressions in (3), this sentence is endowed with properties I have assumed to be inappropriate in the case of $u_{1}$, first and foremost, as I explain in what follows, its flaccid (non-rigid) propensities.

Since rigidity is a modal notion, I briefly rehearse these familiar considerations by appealing to the standard framework for intensional semantics. In this framework, an expression $e$ is associated with an intension [[e]], in turn understood as a function yielding a semantic value (extension) $[[e]](w)$ with respect to a point of evaluation 
$w .{ }^{8}$ Leaving aside as obvious or irrelevant the details pertaining to the interpretation of the verb-phrase in (3), the following hypothesis regarding the intension of the expression in subject position suffices for my purposes: for any definite description $d$ of the form the $F$,

$$
[[d]]=\text { the intension } f \text { such that, for any point } w, f(w)=\text { the unique } i \in[[F]]_{\mathrm{w}}
$$

if any such exists, where $[[e]]_{\mathrm{w}}$ is a more familiar typographical format for $[[e]](w) .{ }^{9}$ As a result, given further obvious semantic clauses, (3) turns out to be true or false with respect to $w$ depending on the political convictions of whoever first served as German Chancellor at $w$, in contrast with the rigid reading assumed as appropriate for (1).

As far as I can tell, something along the lines of (3) may well have been the sort of abbreviation Russell had in mind for sentences containing the ordinary proper name 'Bismarck'. In all likelihood, then, the search for a non-trivial completion of (2) abandons the letter of Russell's descriptivism, and at best pursues what may vaguely be described as a 'Russell-inspired' take on Russell-names. Still, Russellian exegesis aside, the notion that ordinary proper names may be regimented as constructs properly including a definite description has played a prominent role in the contemporary debate between descriptivism and Millianism (and, for that matter, between descriptivism and alternative non-descriptivist viewpoints). Among different options, a particular strategy in this vein deserves to be mentioned at this stage.

According to the view I have in mind, the semantics of proper names is appropriately reflected by certain artificial constructs properly involving definite descriptions: dthat-terms. The semantics for dthat-terms appeals to an apparatus richer than the simple intensional system sketched above, the framework of so-called double-index semantics for indexical intensional languages. ${ }^{10}$ According to the double-index approach, an expression $e$ is assigned an intension $[[e]]_{\mathrm{c}}$ with respect to a context $c$, typically represented as an $n$-tuple including a speaker $c_{a}$, a time $c_{t}$, and a possible world $c_{w} .{ }^{11}$ Consequently, the assignment of semantic values becomes a doublyrelativized affair: $[[e]]_{\mathrm{c}}(w)$, or more concisely $[[e]]_{\mathrm{c}, \mathrm{w}}$, is the semantic value of $e$

\footnotetext{
${ }^{8}$ Throughout these informal sections, I leave aside questions having to do with the relativisation of semantic values to models (see Appendix). For the sake of typographical simplicity, I also eschew mention of assignments of values to variables: my treatment of definite descriptions is easily adaptable to more customary approaches to 'the' as a quantifier, as in 'the $x$ : $F x$ ' (for an overview, see [30]). I also tend to think of points of evaluation merely as possible worlds, but no significant issues arise from alternative accounts (see [21] for a view of points as world-time pairs, and [24] for richer formats).

${ }^{9}$ For reasons of space, I hereinafter simply leave aside issues of non-existence and/or non-uniqueness, and I proceed by leaving the caveat 'if any such exists' as implicit throughout my informal considerations in the main body of this essay.

${ }^{10}$ As noted in [22], 'dthat' has been ambiguously introduced in [21]. Given my focus on intensional semantics, it is the so-called 'rigidifying operator' interpretation that comes to the foreground in the main text of this essay-see footnote 12 for considerations from the viewpoint of propositional semantics.

${ }^{11}$ The characterization of $c_{a}$ as the 'speaker' is (here harmlessly) sloppy, see [21]. In my Appendix, I simplify my exposition by restricting contexts to two parameters, an agent and a possible world.
} 
with respect to a context $c$ and a point of evaluation $w$. Then, given a description $d$ of the form the $F$,

$$
\begin{aligned}
{[[\operatorname{dthat}(d)]]_{\mathrm{c}} } & =\text { the intension } f \text { such that, for any point } w, f(w) \\
& =\text { the unique } i \in[[F]]_{\mathrm{c}, \mathrm{cw}} .
\end{aligned}
$$

As a result, given a few obvious further hypotheses,

\section{(4) dthat(the first Chancellor of the German Empire) was a conservative}

ends up being true or false with respect to a context $c$ and a point of evaluation $w$ iff, given the way things went 'in' $c_{w}$, the class of conservatives in $w$ includes whoever served as German chancellor in $c_{w}$-in the case of 'our context', it ends up being true with respect to a point $w$ iff, in $w$, Otto von Bismarck pursued a right-wing political agenda. $^{12}$

Given my focus in this essay, I can afford to remain indifferent to the question whether anything resembling this dthat-gambit paves the way for a satisfactory treatment of ordinary proper names. ${ }^{13}$ As for Russell-names, the idea that (4) is what is being abbreviated by (1) on the occasion in which $u_{1}$ takes place is a non-starter. This is so because Russell-names are intended to conform to the semantic properties that Millianism attributes to names, and because for a Millian (and for that matter for a considerable number of non-Millians) proper names are not indexical expressions. Yet, as reflected by my mention of 'our context' in the gloss for (4), dthat-terms are indexical, in the sense that they are associated with different intensions with respect to different contexts. As a result, silently taking on board the obvious compositional clauses for (4), [[(4)] $]_{\mathrm{c} 1}$ may be a different intension from $[[(4)]]_{\mathrm{c} 2}$ even if $c l_{w}$ and $c 2_{w}$ agree when it comes to the class of conservatives, as long as different individuals serve as first German Chancellors in those circumstances. ${ }^{14}$

Still, its shortcomings notwithstanding, the dthat-gambit summarized in this section indirectly hints at an intriguing formal stratagem. As I explain in the next section, given certain important modifications, this ploy paves the way for a double-context framework in which Russell-names conform to the desired Millian constraints.

\footnotetext{
${ }^{12}$ Within so-called propositional semantics, sentences are associated with a structured content (with respect to a context), typically represented as an $n$-tuple consisting of the contents of the expressions occurring in them (see for instance [44]). The contribution offered by a directly referential expression to the content of a sentence in which it occurs is customarily characterized as 'an individual', and the corresponding contents are described as singular (see [16] for introductory considerations). According to Kaplan's allegedly 'intended' view of 'dthat' as a device of direct reference, the content of $\operatorname{dthat}(d)$ (at $c$ ) is the unique individual who satisfies $d$ at $c_{w}$ (see [21] and [22]).

${ }^{13}$ For discussions of rigidifying strategies in the vicinity of the dthat-gambit, see among many [6, 21, 22, $33,34,38,43,45-48$ ] and [7]. Rigidifying mechanisms of this sort also typically (though not inevitably) play a role in the increasingly fashionable neo-descriptivist positions roughly inspired by [5] (for different versions, see for instance [1, 2, 12, 17, 23] and [29]). For an interestingly idiosyncratic approach to rigidity (of individual constants within a model-theoretically interpreted formal language) see also [18].

${ }^{14}$ Independently, of course, of any indexical element possibly introduced by the predicate, such as verbal tense. For indexical views of names see [50] and [31]. For criticisms see [21, 22, 32, 35] and [36].
} 


\section{Preliminaries C: Double-Context}

Metaphorically speaking, 'dthat' neutralizes a definite description's sensitivity towards points of evaluation by anchoring its interpretation to an independent relatum: [[(4)] $]_{\mathrm{c}}$ yields Truth at a point $w$ depending solely on the political allegiances of $c_{w}$ 's Chancellor, regardless of the properties of the individual at the head of the German government in $w$. This strategy may naturally be mirrored within the project of a Millian treatment of Russell-names, as long as their associated descriptions are interpreted not only independently of the peculiarities of this or that point of evaluation, but also independently of the parameters relevant for the interpretation of indexical expressions. As I explain in what follows, this much invites a modification of the double-index apparatus from Section 2 into a triply relativized affair-more precisely, for reasons I am about to explain, into a framework in which points of evaluation are accompanied by two contextual parameters.

Recall the informal idea of an association from Section 1, understood as some sort of event in which a Russell-name is associated with a description. Being events involving the use of language, associations take place within a particular setting: at a certain time and in a particular possible world, someone establishes an appropriate relationship between a Russell-name and a description. For reasons that will become apparent as I proceed, a few features of this collection of parameters are worthy of attention, and indirectly provide the intuitive background for my double-context approach to Russell-languages.

These hints are perhaps most perspicuously explained by appealing to associations involving straightforwardly indexical expressions - and, for the sake of clarity, a different exemplar of a Russell-name: 'Napoleon'. Take then an utterance $u_{5}$ of

\section{(5) Napoleon is about to defeat Russia now}

taking place in 1856. According to common consensus, the occurrence of 'now' in this example is to be interpreted with respect to the context for $u_{5}$, presumably a context that includes the time of utterance as its temporal parameter. As a result, given certain further obvious regularities, $u_{5}$ is to be evaluated as true or false depending on the outcome of the conflict in which Russia was involved in 1856, towards the end of the Crimean War. Yet, suppose also that $u_{5}$ is connected with an association that appeals to an overtly indexical description, as in the association $u_{6}$

\section{(6) let 'Napoleon' be associated with 'the Emperor of the French now'}

taking place in 1815. It would seem to be in principle possible to suggest that the interpretation of the indexical 'now' mentioned in (6) ought to be derived on the basis of the context for $u_{6}$, that is, a context with 1815 as its temporal co-ordinate. In other words: it would seem to be in principle possible to demand that $u_{5}$ be evaluated as true iff whoever was Emperor of the French in 1815 is about to defeat Russia in 1856-that is, on the assumption that $u_{5}$ and $u_{6}$ take place in the actual world, iff Napoleon I is within sight of a victorious conclusion to the Crimean War.

I take this suggestion as a promising start for my account of Russell-names. What it entails is a double-context apparatus, with one context, as usual, in charge of 
the interpretation of the indexical overtly appearing at the end of (5), and a different context devoted to identifying the individual determined by the association of 'Napoleon' with the description in (6). I refer to the different roles played by these contexts in terms of the distinction between contexts of interpretation and contexts of association. So (5), or more accurately what it abbreviates on the occasion of $u_{5}$,

... the Emperor of the French now is about to defeat Russia now,

demands to be interpreted by anchoring the occurrences of 'now' respectively to a context of association $k$ and a context of interpretation $c$, such that $k_{t}$ is the time of $u_{6}$, the association of 'Napoleon' with 'the Emperor of the French now', and $c_{t}$ is the time at which $u_{5}$ occurs.

I thus propose a double-context semantic framework for Russell-languages, in which an expression $e$ is assigned an intension $[[e]]_{\mathrm{k}, \mathrm{c}}$ with respect to a context of association $k$ and a context of interpretation $c$, and hence derivatively a semantic value $[[e]]_{\mathrm{k}, \mathrm{c}, \mathrm{w}}$ with respect to $k, c$, and a point of evaluation $w$. In turn, this framework provides the resources needed for the modification of the dthat-gambit to which I alluded at the beginning of this section. I implement this modification in terms of an alternative to 'dthat', an operator 'Rus' defined along the following lines: for any description $d$ of the form 'the $F$ ', contexts $k$ and $c$, and point of evaluation $w$,

$$
\begin{aligned}
{[[\operatorname{Rus}(d)]]_{\mathrm{k}, \mathrm{c}} } & =\text { the intension } f \text { such that, for any } w, f(w) \\
& =\text { the unique } i \in[[F]]_{\mathrm{k}, \mathrm{c}, \mathrm{kw}} .
\end{aligned}
$$

Returning to my original example, and armed with the resources provided by the double-context framework and by ' $R u s^{\prime}$ ', I then propose (7) as a completion of (2), the sentence abbreviated by (1) on the circumstances of $u_{1}$ (sentences repeated for the sake of legibility):

(1) Bismarck was a conservative

(2) ... the first Chancellor of the German Empire was a conservative

(7) Rus(the first Chancellor of the German Empire) was a conservative.

Much remains to be said at this stage. The following sections are devoted to a more rigorous presentation of the hints put forth thus far, and to an explanation of how they provide the background for an analysis of Russell-names compatible with the desiderata put forth at the beginning of this essay. In the next section, I return to the idea of the association of a Russell-name with a definite description, now formally regimented from the viewpoint of the double-context framework informally outlined in this section. In Section 5, I present the semantic properties of the constructs relevant for the semantic evaluation of utterances of Russell-names, namely the Rusterms introduced above, and I explain how they manage to reflect the rigid and non-indexical properties that warrant the occurrence of 'name' in 'Russell-name', according to the Millian view of names. In Section 6, I conclude with the discus- 
sion of certain descriptivist features of Russell-names, and of a few related logical consequences of my approach to Russell-languages.

\section{Semantics A: Utterances and Expansions}

According to the picture from Section 1, a Russell-speaker's utterance of a sentence containing occurrences of a Russell-name is connected with an association. Accordingly, an utterance may formally be represented by coupling the traditional sentence-context representation of utterances with an association, as in

$$
u=<<S, c>, a>
$$

where $S$ is a sentence, $c$ is a context, and $a$ is an association. ${ }^{15}$ Since the semantically relevant components of associations have to do with the pairing of Russell-names with definite descriptions, I further formalize associations as triples consisting of these expressions, side by side with an appropriate contextual parameter. Continuing to focus for simplicity's sake on scenarios involving occurrences of one Russell-name, then, an utterance is now formally understood as a pair

$$
u=<<S, c>,<r, d, k>>
$$

with $S$ and $c$ as above, $r$ a Russell-name, $d$ a description, and $k$ a context. In an informal gloss of this format, (8) expresses the idea of an utterance of $S$ in a context (of interpretation) $c$, connected with an association in a context (of association) $k$ of the Russell-name $r$ with the description $d$. For instance, the utterance $u_{1}$ from Section 1 ends up being representable as the pair

(9) $u_{1}=<<$ Bismarck was a conservative, $c>$, $<$ Bismarck, the first Chancellor of the German Empire, $k>>$

with $c$ and $k$ including the speaker, time, etc. appropriate respectively for that utterance and for the association with which it is connected.

In these informal sections, my Russell-language of choice includes a few not further analysed predicates ('was a conservative', 'is about to defeat Russia now'), side by side with a couple of Russell-names ('Bismarck', 'Napoleon'; see the Appendix for a more precise presentation of a formal Russell-language $L_{R}$ ). I refer to the language appropriate for the presentation of the constructs abbreviated by Russell-names as that Russell-language's expansion (in the Appendix, $L *_{R}$ ). In my presentation thus far, such an expansion is deprived of Russell-names, but is endowed with a stock of definite descriptions ('the first Chancellor of the German Empire', 'the French Emperor now') and with the operator Rus. According to the idea of abbreviation

\footnotetext{
${ }^{15}$ For the formal understanding of 'utterance' as a sentence-context pair see [21]. The idea of association is here formalized along lines appropriate for my simple examples involving occurrences of one Russellname - the generalization to instances with a plurality of these expressions is straightforward.
} 
described in Section 1, then, given an association $<r, d, k>$, a sentence $S$ of a Russell-language abbreviates a sentence $S^{*}$ of its expansion, where $S^{*}$ results from $S$ by substituting all occurrences of $r$ in $S$ with $\operatorname{Rus}(d)$. So, for instance, given the association appropriate for $u_{1}$, namely the association described by the second member of (9), (1) abbreviates (7), the result of substituting 'Bismarck' with 'Rus(the first Chancellor of the German Empire)'.

Finally, let the expansion of an utterance $u$ of the form (8) be the triple

$$
u^{*}=<S^{*}, c, k>
$$

that is, the triple consisting of the sentence abbreviated by $S$ on the occasion of $u$, of the context of interpretation appropriate for $u$, and of the context for its connected association. ('Expansion' thus ambiguously applies to languages and utterances, but no confusion is likely to arise from this equivocation). In the case of $u_{1}$, for instance, its expansion is the triple

$u_{1} *=<\operatorname{Rus}$ (the first Chancellor of the German Empire) was a conservative, $c$, $k>$

with $c$ and $k$ as above.

In turn, these ideas provide the background for a more precise formulation of the notion that the semantic interpretation of a Russell-speaker's utterance 'depends on' the semantic properties of a certain description-involving construct. In particular, I define a predicate 'true' for utterances of sentences in a Russell-language as follows: given an utterance $u$ whose expansion is $u^{*}=<S^{*}, c, k>$,

$$
\text { true }(u) \text { iff } \text { true }_{c, k}\left(\mathrm{~S}^{*}\right) \text {, }
$$

given a not yet explained a predicate true $_{c, k}$ for sentences in the expansion of that Russell-language. ${ }^{16}$ So, for example, $u_{1}$ ends up being evaluated as true exactly on the condition that (7) is true $_{k, c}$, where $k$ and $c$ are as in (9).

The analysis of true $_{c, k}$ is the topic of the next section, devoted to the compositional analysis of sentences in a Russell-language's expansion. Since the characteristic feature of this language has to do with the presence of Rus-terms, I focus my presentation on the resources required for their interpretation, starting with the reflection of the informal notion of 'meaning' within a double-context framework. The resulting distinction between the classic idea of character and what I call an expression's 'countenance' leads me to the explanation of how Rus-terms, and hence derivatively Russell-names, are endowed with constant characters and constant intentions, consistently with the Millian demands of non-indexicality and rigidity. In Section 6 , I conclude with the discussion of certain 'logical' properties ensuing from my definition of true $_{c, k}$, which in turn indirectly highlight certain properties of Russelllanguages and of their expansions that are particularly palatable from a descriptivist viewpoint.

\footnotetext{
${ }^{16}$ Mutatis mutandis, a parallel strategy may be implemented for other semantic notions, such as the idea of 'content' from the viewpoint of a propositional framework.
} 


\section{Semantics B: Countenance and Character}

In the standard framework for indexical languages, expressions are assigned a certain primitive semantic property, character, formally understood as a function from contexts to intensions. ${ }^{17}$ So, the character $\{e\}$ of an expression $e$ is the function which, given a context $c$ as its argument, yields $\{e\}(c)$, or, in the notation from Section 2, $[[e]]_{\mathrm{c}}$, the intension of $e$ with respect to $c .{ }^{18}$

In my double-context framework, on the other hand, what is endowed with a character is not an expression simpliciter, but a pair consisting of an expression and a context (of association), as in: $\{e, k\}$, the character of $e$ with respect to $k$. In particular, as indicated above, Rus-terms are endowed with a certain character with respect to a context $k_{1}$, but with a possibly distinct character with respect to a different context $k_{2}$. For instance,

\section{$\left\{\right.$ Rus(the first Chancellor of the German Empire), $\left.k_{1}\right\}$}

is the constant character $f_{1}$ such that, for any context $c, f_{1}(c)$ is the constant intension yielding the unique individual who served as the first Chancellor of the German Empire in $k_{1 w}$. But

\section{$\left\{\right.$ Rus(the first Chancellor of the German Empire), $\left.k_{2}\right\}$}

is the distinct constant character $f_{2}$ responsible for the constant intension concerned with whoever preceded all other Imperial Chancellors in $k_{2 w}$.

From the viewpoint of double-context semantics, then, character is a derived semantic property, systematically obtainable on the basis of a certain primitive property of an expression, together with a context. I call this property of an expression $e$ its countenance, written as $|e|$ and understood as a function from contexts (of association) to characters. In particular,

\section{$\mid$ Rus(the first Chancellor of the German Empire) $\mid$}

is the countenance $g$ such that, for any context $k, g(k)$ is the character $\{R u s($ the first Chancellor of the German Empire), $k\}$ of the kind described in the foregoing paragraph. ${ }^{19}$

In the standard framework for indexical languages, sentences are assigned a semantic-value (truth-value) with respect to a context and a point, according to the customary compositional regularities—as in $[[S]]_{\mathrm{c}, \mathrm{w}}$, the truth-value of $S$ with

\footnotetext{
${ }^{17}$ I label this property as semantically 'primitive' in the sense that, in a classic framework for indexical intensional languages, the character of an expression is a fundamental, non-derived property-in the case of a model-theoretic approach to non-fully interpreted languages, a property that is attributed to nonconstant expressions by the model's interpretation function, see [21].

${ }^{18}$ I borrow this notation from [21]; for comments on character see among others [3].

${ }^{19}$ From a propositional viewpoint, of course, the definition of ' $R u s$ ' is to be adapted so as to obtain results consistent with the demands of direct referentiality, as in (roughly): for any $k$ and $c$, the content of Rus(the first Chancellor of the German Empire) is the unique individual $\{$ Rus (the first Chancellor of the German Empire), $k\}\left(k_{w}\right)$.
} 
respect to $c$ and $w$. A singly relativized predicate true $_{c}$ is then standardly defined as in

$$
\operatorname{true}_{\mathrm{c}}(S) \text { iff }[[S]]_{\mathrm{c}, \mathrm{cw}}=\mathrm{T},
$$

i.e., iff $S$ is assigned the semantic value T with respect to $c$ and the point determined by $c .^{20}$ Unsurprisingly, a similar move within a double-context framework yields doubly-relativized truth-predicates, such as, in particular,

$$
\text { true }_{\mathrm{k}, \mathrm{c}}(S) \text { iff }[[S]]_{\mathrm{k}, \mathrm{c}, \mathrm{cw}}=\mathrm{T} \text {. }
$$

Swiftly adapting these remarks to the case of (7), repeated here

(7) Rus(the first Chancellor of the German Empire) was a conservative,

true $_{\mathrm{k}, \mathrm{c}}(7)$ iff (7) is assigned the semantic value $\mathrm{T}$ when evaluated with respect to the contexts $k$ and $c$ and the point $c_{w}$, that is, iff the first German Chancellor in $k_{w}$ is such that he is a conservative in $c_{w}$. Since, according to (10) from Section 4, an utterance with $\left\langle S *, k, c>\right.$ as its expansion is true iff $\operatorname{true}_{k, c}(S *)$, it follows that $u_{1}$, the utterance of (1) from Section 1, is true as long as whoever has been identified as the first Chancellor of the German Empire in the context of association $k$ is a conservative at the possible world where $u_{1}$ takes place. In other words, assuming $u_{1}$ to take place in the actual world, it follows that $\operatorname{true}\left(u_{1}\right)$, since true $\mathrm{e}_{\mathrm{c}, \mathrm{k}}(7)$, that is, since Otto von Bismarck was in fact a conservative.

As usual, the definition of a truth-predicate gives rise to corresponding 'meaninggrounded' notions, as in the informal idea of a sentence's being 'true by virtue of meaning alone'. Given the classic notion of $t r u t h c$ for indexical languages, for instance, this idea is formally reflected in terms of truth by virtue of character alone, that is, in terms of $\operatorname{truth}_{c}$ for all $c .^{21}$ Since the development of a double-context apparatus engenders doubly-relativized predicates such as true $_{k, c}$, a formal rendering of the notion of 'meaning guaranteed truth' must then be cashed out in terms of 'countenance guaranteed' truth, that is, in terms of $\operatorname{truth}_{k, c}$ for all $k$ and $c$. After a few further clarifications and developments, I devote the final section of this essay to a preliminary study of some properties of this notion, in turn intended as an exploration of certain descriptivists consequences of the idea of a Russell-name within a double-context framework.

\section{Semantics C: Countenance and Designation}

Not unlike the eight-letter name-type 'Bismarck', the Russell-name-type 'Bismarck' is in itself deprived of a semantic profile: what constitute the objects of semantic evaluation are, as common parlance puts it, 'uses' of these expressions. In the case of Russell-names, what is of semantic interest is, in colloquial terms, 'Bismarck' qua

\footnotetext{
${ }^{20}$ See [21] and [26].

${ }^{21}$ In the model theoretic analysis of the formal language $L_{D}$ in [21], this idea is developed in terms of truth in all models and contexts, in turn labeled by Kaplan as analyticity.
} 
abbreviation of, say, 'Rus(the first Chancellor of the German Empire)', rather than of 'Rus(the largest German battleship in 1940)' or for that matter 'Rus(the 1872 Minister President of Prussia)'. ${ }^{22}$ In the more theoretically laden terms from the foregoing sections: what matters is 'Bismarck' as it occurs in an utterance connected with an association involving, say, 'the first Chancellor of the German Empire', rather than some other description.

Even with our attention firmly focused on the 'first Chancellor' scenario, 'Bismarck' is strictly speaking only indirectly endowed with a semantic profile. Indeed, as hinted thus far and as more explicitly put forth in the Appendix, the immediate objects of compositional evaluation are not Russell-languages but their expansionsthat is, languages deprived of Russell-names but equipped with Rus-terms in their stead. Yet, given certain obvious background assumptions, a more direct and concise presentation ought to remain intelligible as a harmless shorthand for the officially authorized but cumbersome jargon. 'Bismarck', I write henceforth, is endowed with the countenance

\section{$\mid R u s($ the first Chancellor of the German Empire)|,}

in the sense that utterances of 'Bismarck' in the by now familiar circumstances are evaluated on the basis of the semantic properties of that Rus-term, along the lines indicated thus far.

In an equally harmlessly colloquial sense, then, 'Bismarck' may be described as designating an individual $i$ with respect to a context (of association) $k$. In particular,

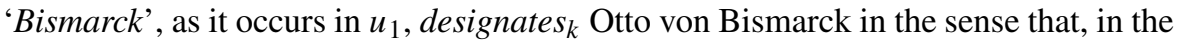
context of association $k$ appropriate on that occasion,

\section{$\mid$ Rus(the first Chancellor of the German Empire| $(k)$}

is a constant character concerned with that man. So, as indirectly indicated by this relativisation of the designation-relation, Russell-names conform to the satisfactional pattern characteristic of descriptivism: the relationship between 'Bismarck' and Bismarck is not semantically immediate, but results from the interaction between a descriptive condition and the idiosyncrasies of this or that context.

Still, although the identification of a Russell-name's designation is in a sense a contextual business, it is clearly not a 'contextual business' in the sense of contextuality appropriate for indexicality. Indeed, in consonance with the Millian requirements put forth at the beginning of this essay, Russell-names are endowed with a constant character, and persist in their relationship with a particular designatum across occasions of utterance (or, as I put it, across contexts of interpretation). As a result, their satisfactional requirements fail to interact with those of overtly indexical expressions. Returning to example (5) from Section 3, for instance,

(5) Napoleon is about to defeat Russia now

\footnotetext{
${ }^{22}$ The former example is an allusion to the Garman battleship Bismarck, destroyed by the British fleet in 1941. The latter appeals to Otto von Bismarck's role as Minister President of Prussia, roughly concomitant with his position as Chancellor of the German Empire.
} 
may well truly be utterable as a description of a scenario in which, for no time $t$, whoever is French Emperor at $t$ is in sight of victory over Russia at $t$, even on the assumption of an association of 'Napoleon' with 'the Emperor of the French now'see $u_{6}$ in Section 3.

Accordingly, then, Russell-names display a particularly idiosyncratic satisfactional pattern: though sensitive to the peculiarities of this or that context of association, their designation remains non-indexically indifferent to contexts of interpretation, and rigidly unconcerned with points of evaluation. In the doublecontext apparatus put forth thus far, this pattern is implemented in terms of the distinction between countenance and character: in the case of Russell-names (or, more precisely, their representative Rus-terms), character is a derived semantic property, obtainable on the basis of their countenance and of the choice of a particular context of association. As I am about to explain in the remainder of this section, this distinction yields interesting semantic consequences, which at least partly reflect the sense in which Russell-names conform to certain descriptivist desiderata.

Unsurprisingly, a notorious type of example turns out to be particularly apt for guiding my discussion of this topic: true identity statements such as, in the case of ordinary proper names,

\section{(11) Hesperus is Phosphorus}

with 'Hesperus' and 'Phosphorus' used qua names of Venus. From the viewpoint of the standard framework for indexical intensional languages, the Millian treatment of proper names entails that their semantic behaviour is fully reflected by a constant character responsible for the identification of (a constant intension yielding) what is commonly called its 'referent'. Since, as mentioned, character is accordingly understood as a non-derived reflection of an expression's meaning, sentences such as (11) end up being true by virtue of character, that is, true in some sort of 'meaning guaranteed' way. ${ }^{23}$

The characteristically descriptive profile of Russell-names within the accompanying double-context apparatus is profitably highlighted by contrasting these conclusion with the outcomes ensuing in parallel scenarios involving Russell-names. Take for instance

\section{(12) Hesperus is Phosphorus,}

and assume that these Russell-names are associated with the obvious descriptive material, say, respectively 'the first object visible in the evening sky' and 'the last object visible in the morning sky'. Given any context $k$ such that $k_{w}$ is astronomically sufficiently similar to the actual world, these Russell-names co-designate . $_{\text {. }}$ More precisely, for any such $k$, the character

\footnotetext{
${ }^{23}$ As a result, the Millian commitments to rigidity and non-indexicality are commonly reflected in terms of the slogans that the meaning of a name 'is simply its bearer [39], i.e., that it is 'the object to which it refers' (Braun [4]: 491).
} 
$\mid R u s$ (the first object visible in the evening sky| $(k)$

is the very same character as

$\mid$ Rus(the last object visible in the morning sky| $(k)$,

namely the constant function yielding (a constant intension yielding) Venus at all contexts. Accordingly, the identity claim in (12), or more precisely

$\mid$ Rus(the first object visible in the evening sky $|=| R u s$ (the last object visible in the morning sky|

is indeed once again recognized as true by virtue of character alone, in the sense that, given a context of association $k$ as above, true $\mathrm{k}_{\mathrm{k}, \mathrm{c}}(13)$ for all $c$. Yet, a conclusion of this sort is hardly amenable to an informal gloss in terms of 'meaning guaranteed' truth: as a result of the derivative status of character in a double-context framework, truth by virtue of character is achieved not only on the basis of the conventional properties of 'Hesperus' and 'Phosphorus' (and, of course, 'is'), but also on the basis of the peculiarities of $k$, the context of association I have chosen for my example. The sense in which truth is inevitably obtained independently of the idiosyncratic aspects of this or that context (and, of course, of this or that point of evaluation) is rather now reflected by the idea of $t r u t h_{k, c}$ for all $k$ and $c$. And, clearly, for some $k$ (and $c$ ), not true $_{\mathrm{k}, \mathrm{c}}(13)$-in particular, for any $k$ such that, at $k_{w}$, the heavenly body that appears first in the evening sky is distinct from what lingers in the morning firmament. ${ }^{24}$

\section{Conclusion}

Are there occurrences of Russell-names in English? In this essay, I remained deliberately silent when it comes to this question. As a result, my conclusions remain compatible with the ideas that (i) all expressions we commonly classify as proper names are Russell-names, (ii) some of them are, or (iii) none of them are.

It is perhaps option (ii) that deserves particular attention from the viewpoint of natural language semantics, at least given the recurrent suspicion that some expressions commonly classified as proper names display idiosyncratic semantic properties not shared by run-of-the mill, 'prototypical' names. ${ }^{25}$ Admittedly, in the absence of

\footnotetext{
${ }^{24}$ These conclusions (if flanked by a variety of independent considerations) may in turn be of relevance for a family of issue in philosophical psychology and the philosophy of mind, commonly gathered under the label of 'cognitive value'. It is in this respect that the details in what I called the 'connection' relation between utterances and associations may deserve a much more attentive and detailed treatment than the highly tentative hints in footnote 7 . Due to this essay's focus on issues in truth-conditional semantics, I leave these independently interesting issues as a topic for future developments of the idea of a Russelllanguage, and of its relation with Russell-speakers.

${ }^{25}$ Some possibly promising areas of application may have to do with the various issues commonly subsumed under the label of 'descriptive names' (see among many [11, 13-15, 19, 25, 48, 49] and [20]). A distinct phenomenon perhaps amenable to a treatment grounded on the idea of Russell-names has to do with so-called 'names that have grown capitals' (see Corazza [8] and Rabern [37]). These prima facie applications of my apparatus will unquestionably need to be assessed in their own right, on the basis of considerations independent of my assessment of the relationships between Millianism and descriptivism.
} 
arguments to this effect, option (iii) remains a possibility that should not be dismissed off hand. Yet, if Russell-names turn out to be nothing more that a philosopher's concoction, they do so only on the basis of considerations independent of the core Millian picture of proper names as rigidly non-indexical, and of the arguments typically presented in its defence. Conversely, considerations supporting (at least some type of) a descriptivist approach to proper names may well lead Millians towards the direction of (i), or at least (ii), with no embarrassment for their commitment to a nonflaccid and non-indexical treatment of those expressions. The semantic admissibility of Russell-names thus opens an interesting conceptual niche in the traditional divide between Millian and descriptivist approaches to proper names, and paves the way for a more fruitful dialogue between these traditionally incompatible stances.

Open Access This article is distributed under the terms of the Creative Commons Attribution 4.0 International License (http://creativecommons.org/licenses/by/4.0/), which permits unrestricted use, distribution, and reproduction in any medium, provided you give appropriate credit to the original author(s) and the source, provide a link to the Creative Commons license, and indicate if changes were made.

\section{Appendix}

\section{(1) The Russell-Language L}

Lexicon $_{\mathrm{L}}$

1. A set $\mathrm{IC}_{\mathrm{L}}$ of individual constants

2. A set $\mathrm{PR}_{\mathrm{L}}$ of one-place predicates

3. The indexical $i$; the determiner the; the modal operator Nec

4. A set $\mathrm{RN}_{\mathrm{L}}$ of Russell-names

Syntax $_{\mathrm{L}}$

- for any $F \in \mathrm{PR}_{\mathrm{L}}$, the $F$ is a description $\mathrm{L}_{\mathrm{L}}\left(\mathrm{D}_{\mathrm{L}}\right)$

- for any $t$ such that $t \in \mathrm{IC}_{\mathrm{L}} \cup \mathrm{RN}_{\mathrm{L}} \cup\{i\} \cup \mathrm{D}_{\mathrm{L}}, t$ is a term $_{L}$

- and any term $t$ and $F \in \mathrm{PR}_{\mathrm{L}}, F(t)$ is a sentence $\mathrm{L}_{\mathrm{L}}$

- for any sentence $\mathrm{L}, \operatorname{Nec}(S)$ is a sentence L $_{\mathrm{L}}$

(2) The Expansion $L^{*}$

\section{Lexicon $_{L^{*}}$}

- $\mathrm{IC}_{\mathrm{L}^{*}}=\mathrm{IC}_{\mathrm{L}}$

- $\quad \mathrm{PR}_{\mathrm{L}^{*}}=\mathrm{PR}_{\mathrm{L}}$

- The indexical $i$; the determiner the; the modal operator Nec

- The operator Rus

\section{Syntax $_{L^{*}}$ :}

- for any $F \in \mathrm{PR}_{\mathrm{L}^{*}}$, the $F$ is a description $\mathrm{L}^{*}\left(\mathrm{D}_{\mathrm{L}^{*}}\right)$

- for any $d \in \mathrm{D}_{\mathrm{L}^{*}}, \operatorname{Rus}(d)$ is a Rus-term $\mathrm{L}^{*}\left(\mathrm{RT}_{\mathrm{L}^{*}}\right)$

- for any $t$ such that $t \mathrm{i} \in \mathrm{IC}_{\mathrm{L}^{*}} \cup\{i\} \cup \mathrm{D}_{\mathrm{L}^{*}} \cup \mathrm{RT}_{\mathrm{L}^{*}}, t$ is a term $_{L^{*}}$

- for any term $\mathrm{L}^{*} t$ and $F \in \mathrm{PR}_{\mathrm{L}^{*}}, F(t)$ is a sentence $\mathrm{L}^{*}$

- for any sentence $\mathrm{L}^{*} S, N e c(S)$ is a sentence $\mathrm{L}^{*}$ 


\section{(3) Utterances, Associations, Expansions}

- Let the class of contexts $C$ be such that, for all $c \in C, c=<c_{a}, c_{w}>, c_{a}$ an individual and $c_{w}$ a possible world

- For any $d \in \mathrm{D}_{\mathrm{L}}, r \in \mathrm{RN}_{\mathrm{L}}$, and $k \in C,<r, d, k>$ is an association $_{L}$

- For any sentence $\mathrm{L}, c \in C$, and association $_{\mathrm{L}}, a$, the pair $<<S, c>, a>$ is an utterance $_{L}$

- For any utterance $\mathrm{L} u$ of the form $<<S, c>, a>$, with $a=<r, d, k>$, the expansion of $u$ is the triple $\left\langle S *, c, k>\right.$, where $S *$ is the sentence $\mathrm{L}^{*}$ resulting from $S$ by replacing occurrences of $r$ with $\operatorname{Rus}(d)$

(4) Semantics for L*: Models

A $\mathrm{L}^{*}$-model $\mathrm{M}$ is a quadruple $<\mathrm{U}^{\mathrm{M}}, \mathrm{W}^{\mathrm{M}}, \mathrm{I}^{\mathrm{M}}, \mathrm{C}^{\mathrm{M}}>$ such that

- $\mathrm{U}^{\mathrm{M}}$ is a non-empty class of individuals

- $\mathrm{W}^{\mathrm{M}}$ is a non-empty class of possible worlds

- $\quad \mathrm{C}^{\mathrm{M}}$ is a non-empty class of pairs $\left\langle c_{a}, c_{w}\right\rangle$, with $c_{a} \in \mathrm{U}^{\mathrm{M}}$ and $c_{w} \in \mathrm{W}^{\mathrm{M}}$

- $\mathrm{I}^{\mathrm{M}}$ is a function such that, for any $c, k \in \mathrm{C}^{\mathrm{M}}$ and $w \mathrm{~W}^{\mathrm{M}}$,

- for any $a \in \mathrm{IC}_{\mathrm{L}^{*}}, \mathrm{I}^{\mathrm{M}}(a)=$ a constant function $f$ such that $f(k)=\mathrm{a}$ constant function $g$ such that $g(c)=$ a constant function $j$ such that $j(w) \in \mathrm{U}^{\mathrm{M}}$

○ for any $F \in \mathrm{PR}_{\mathrm{L}^{*}}, \mathrm{I}^{\mathrm{M}}(F)=$ a constant function $f$ such that $f(k)=$ a constant function $g$ such that $g(c)=$ a function $j$ such that $j(w) \subseteq$ $\mathrm{U}^{\mathrm{M}}$

\section{(5) Semantics for L*: Countenance and Character}

The countenance $|\mathrm{e}|^{\mathrm{M}}$ of an expression $e$ of $L *$ in a model $M$ is a function such that, for any $c, k \in \mathrm{C}^{\mathrm{M}}$ and $w \in \mathrm{W}^{\mathrm{M}}$,

- for any $a \in \mathrm{IC}_{\mathrm{L}^{*}},|a|^{\mathrm{M}}=\mathrm{I}^{\mathrm{M}}(a)$

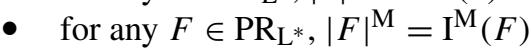

- $|i|^{\mathrm{M}}=$ the constant function $f$ such that $f(k)=$ the function $g$ such that $g(c)=$ the constant function $j$ such that $j(w)=c_{a}$

- for any $F \in \mathrm{PR}_{\mathrm{L}^{*}}, \mid$ the $\left.F\right|^{\mathrm{M}}=$ the constant function $f$ such that $f(k)=$ the constant function $g$ such that $g(c)=$ the function $j$ such that $j(w)=$ the unique $i \in \mathrm{U}^{\mathrm{M}}$ such that $|\mathrm{F}|^{\mathrm{M}}(k)(c)(w)$ if such $i$ exists, and $\dagger$ otherwise. ${ }^{26}$

- for any $F \in \mathrm{PR}_{\mathrm{L}^{*}}, \mid$ Rus $\left.($ the $F)\right|^{\mathrm{M}}=$ the function $f$ such that $f(k)=$ the constant function $g$ such that $g(c)=$ the constant function $j$ such that $j(w)=$ the unique $i \in \mathrm{U}^{\mathrm{M}}$ such that $|\mathrm{F}|^{\mathrm{M}}(k)(c)\left(k_{w}\right)$ if such $i$ exists, and $\dagger$ otherwise.

- Notation: $\{e, k\}^{\mathrm{M}}=|e|^{\mathrm{M}}(k)$ (the character in the model $M$ of the expression $_{\mathrm{L}^{*}} e$ with respect to a context $k$ )

(6) Semantics for L*: Semantic Value

\footnotetext{
26 ' $\dagger$ is a completely alien entity, [not in] $\mathrm{U}^{\mathrm{M}} \ldots$, which represents an 'undefined' value of the function' (Kaplan 1977: 544). This solution is here adopted merely for the sake of illustration.
} 
- $\quad$ Notation: $[[e]]_{\mathrm{k}, \mathrm{c}, \mathrm{w}}^{\mathrm{M}}=\{e, k\}^{\mathrm{M}}(c)(w)$ (the semantic value in the model $M$ of the expression $\mathrm{L}^{*} e$ with respect to contexts $k$ and $c$ and possible world $w$ )

- $\quad$ For any sentence $\mathrm{L}^{*} S$ of the form $F(t), F \in \mathrm{PR}_{\mathrm{L}^{*}}$ and $t$ a term $\mathrm{L}^{*},[[\mathrm{~S}]]_{\mathrm{k}, \mathrm{c}, \mathrm{w}}^{\mathrm{M}}=$ $\mathrm{T}$ iff $[[\mathrm{t}]]_{\mathrm{k}, \mathrm{c}, \mathrm{w}}^{\mathrm{M}} \in[[\mathrm{F}]]_{\mathrm{k}, \mathrm{c}, \mathrm{w}}^{\mathrm{M}}$

- For any sentence $\mathrm{L}^{*} S$ of the form $N e c\left(S_{1}\right),[[S]]_{\mathrm{k}, \mathrm{c}, \mathrm{w}}^{\mathrm{M}}=\mathrm{T}$ iff $\left[\left[S_{1}\right]\right]_{\mathrm{k}, \mathrm{c}, \mathrm{w} *}^{\mathrm{M}}$ for all $w * \in \mathrm{W}^{\mathrm{M}}$

\section{(7) Truth}

- For any sentence $\mathrm{L}^{*} S$ and $k, c \in C^{M}$, $\operatorname{true}_{\mathrm{k}, \mathrm{c}}^{\mathrm{M}}(S)$ iff $[[S]]_{\mathrm{k}, \mathrm{c}, \mathrm{cw}}^{\mathrm{M}}=\mathrm{T}$

- For any sentence $\mathrm{L}^{*} S$, analytic(S) iff true $\mathrm{k}_{\mathrm{k}, \mathrm{c}}^{\mathrm{M}}$ for all $M$ and $k, c \in C^{M}$

- For any utterance $\mathrm{L} u$ of the form $<S, \mathrm{c}>,<\mathrm{r}, \mathrm{d}, \mathrm{k}>>$, true $(u)$ iff $\operatorname{true}_{c, k}(S *)$, with $c, r, d, k$, and $S *$ as in (3).

\section{References}

1. Bach, K. (1981). What's in a Name. Australasian Journal of Philosophy, 59(4), 371-386.

2. Bach, K. (2002). Giorgione Was So-Called Because of His Name. Philosophical Perspectives, 16, $73-$ 103 .

3. Braun, D. (1995). What Is Character? Journal of Philosophical Logic, 24, 227-240.

4. Braun, D. (2006). Names and Natural Kind Terms, In E. Lepore, \& B. Smith (Eds.), The Oxford Handbook of Philosophy of Language (pp. 490-515): Oxford University Press.

5. Burge, T. (1973). Reference and Proper Names. Journal of Philosophy, 70, 425-39.

6. Caplan, B. (2005). Against Widescopism. Philosophical Studies, 125(2), 167-190.

7. Caplan, B. (2007). Millian Descriptivism. Philosophical Studies, 33, 181-198.

8. Corazza, E. (2002). Description-Names. Journal of Philosophical Logic, 31, 313-325.

9. Devitt, M. (1981). Designation: Columbia University Press.

10. Dickie, I. (2011). How Proper Names Refer. Proceedings of the Aristotelian Society, 111, 43-78.

11. Donnellan, K. (1970). Proper Names and Identifying Descriptions. Synthese, 21, 335-358.

12. Elbourne, P. (2005). Situations and Individuals: MIT Press.

13. Evans, G. (1973). The Causal Theory of Names. Proceedings of the Aristotelian Society. Supplementary, 47, 187-208.

14. Evans, G. (1982). The Varieties of Reference: Clarendon Press.

15. Evans, G. (1985). Collected Papers: Clarendon Press.

16. Fitch, G., \& Nelson, M. (2014). Singular Propositions. The Stanford Encyclopedia of Philosophy (Fall 2014 Edition). In Edward N. Zalta (Ed.) http://plato.stanford.edu/archives/fall2014/entries/ propositions-singular/.

17. Geurts, B. (1997). Good News About the Description Theory of Names. Journal of Semantics, 14, 319-348.

18. Glüer, K., \& Pagin, P. (2006). Proper Names and Relational Modality. Linguistics and Philosophy, 29, 507-535.

19. Jeshion, R. (2004). Descriptive Descriptive Names, In M. Reimer, \& A. Bezuidenhout (Eds.), Descriptions and Beyond: Oxford University Press.

20. Kanterian, E. (2009). Puzzles About Descriptive Names. Linguistics and Philosophy, 32, 409-428.

21. Kaplan, D. (1977). Demonstratives (ms.). Reprinted In J. Almog, J. Perry, \& H. Wettstein (Eds.), Themes from Kaplan (pp. 481-563). Oxford: Oxford University Press.

22. Kaplan, D. (1989). Afterthoughts, In J. Almog, J. Perry, \& H. Wettstein (Eds.), Themes From Kaplan (pp. 565-614): Oxford University Press.

23. Katz, J. (1990). Has the Description Theory of Names Been Refuted? In G. Boolos (Ed.), Meaning and Method: Essays in Honour of Hilary Putnam: Cambridge University Press.

24. Kölbel, M. (2002). Truth Without Objectivity: Routledge.

25. Kripke, S. (1980). Naming and Necessity, 2nd edn: Harvard University Press. 
26. Lewis, D. (1980). Index, Context and Content, In S. Kanger, \& S. Öhman (Eds.), Philosophy and Grammar. Reidel. Reprinted in D Lewis, Papers in Philosophical Logic (pp. 21-44): Cambridge University Press.

27. Marti, G. (1995). The Essence of Genuine Reference. Journal of Philosophical Logic, 275-289.

28. Marti, G. (2003). The Question of Rigidity in New Theories of Reference. Nous, 37, 161-179.

29. Matushansky, O. (2008). On the Linguistic Complexity of Proper Names. Linguistics and Philosophy, 21, 573-627.

30. Neale, S. (1990). Descriptions: MIT Press.

31. Pelczar, M., \& Rainsbury, J. (1998). The Indexical Character of Names. Synthese, 114, 293-317.

32. Perry, J. (2001). Reference and Reflexivity: CSLI.

33. Plantinga, A. (1974). The Nature of Necessity: Clarendon Press.

34. Plantinga, A. (1978). The Boethian Compromise. American Philosophical Quarterly, 15, 129-138.

35. Predelli, S. (2001). Names and Character. Philosophical Studies, 103, 145-163.

36. Predelli, S. (2009). Socrates and 'Socrates'. American Philosophical Quarterly, 46, $203-212$.

37. Rabern, B. (2014). Descriptions Which Have Grown Capital Letters. Mind and Language. version 22.02.14.

38. Recanati, F. (1993). Direct Reference: From Language to Thought: Blackwell.

39. Reimer, M. (2010). Reference, In E. Zalta (Ed.), The Stanford Encyclopedia of Philosophy (Spring 2010 Edition). http://plato.stanford.edu/archives/spr2010/entries/reference/.

40. Russell, B. (1905). On Denoting. Mind, 14, 479-93.

41. Russell, B. (1911). Knowledge by Acquaintance and Knowledge by Description. Proceedings of the Aristotelian Society, 11, 108-128.

42. Russell, B. (1918). Lectures on the Philosophy of Logical Atomism. Monist 28-9. Reprinted In R. C. Marsh (Ed.), Logic and Knowledge (pp. 177-281): George Allen and Unwin.

43. Salmon, N. (1981). Reference and Essence: Princeton University Press.

44. Salmon, N. (1986). Frege's Puzzle: MIT Press.

45. Soames, S. (1995). Beyond Singular Propositions. Canadian Journal of Philosophy, 25, 515-550.

46. Soames, S. (1998). The Modal Argument: Wide Scope and Rigidified Description. Nous, 32, 1-22.

47. Soames, S. (2002). Beyond Rigidity: the Unfinished Semantic Agenda of Naming and Necessity: Oxford University Press.

48. Soames, S. (2003): Princeton University Press.

49. Soames, S. (2007). Descriptive Names vs. Descriptive Anaphora. Philosophy and Phenomenological Research, 72, 665-673.

50. Voltolini, A. (1995). Indexinames, In J. Hill, \& P. Kotatko (Eds.), Karlovy Vary Studies in Reference and Meaning (pp. 258-285). 